\title{
Fabrication and dynamics of two layers vanadium carbide reinforced iron matrix surface composite
}

\author{
Fan Bai ${ }^{1}$, Li-sheng Zhonga, ${ }^{a}$, Xin Wang ${ }^{1}$, Yun-hua Xu' ${ }^{1}$, Zi-yuan Zhao ${ }^{1}$ \\ ${ }^{1}$ School of Materials Science and Engineering, Xi'an University of Technology, Xi'an 710048, China
}

\begin{abstract}
Vanadium carbide particulates-reinforced iron matrix composites were prepared by in situ solid-phase diffusion method with different heat treatment times $(30,60,120$ and $240 \mathrm{~min})$ at $1223 \mathrm{~K}, 1273 \mathrm{~K}$ and $1323 \mathrm{~K}$ after high temperature treatment at $1373 \mathrm{~K}$ for $5 \mathrm{~min}$. The surface vanadium carbide layers $\left(\mathrm{V}_{2} \mathrm{C}\right.$ layer and $\mathrm{V}_{8} \mathrm{C}_{7}$ layer $)$ were characterized by means of scanning electron microscopy and X-ray diffraction. The kinetics of vanadium carbide layers showed that a parabolic relationship between carbide layer thickness and treatment time, which indicating that the composite layer's growth is controlled by diffusion. The apparent activation energy of $\mathrm{V}_{2} \mathrm{C}$ layer and $\mathrm{V}_{8} \mathrm{C}_{7}$ layer were $47.27 \mathrm{~kJ} / \mathrm{mol}$ and $32.26 \mathrm{~kJ} / \mathrm{mol}$, respectively.
\end{abstract}

\section{Introduction}

It is well known that vanadium carbide is one of the most appropriate reinforcement for iron matrix surface composite, which due to its high hardness, good thermal stability, and well wettability with iron matrix [1]. Vanadium carbide reinforced iron matrix surface composite shows excellent wear resistance and high temperature properties, which can be widely used in metallurgy, mining, power, machinery, and water conservancy [2]. The diffusion dynamics based on the Arrhenius equation of carbide coating [3], boride coating [4], and nitrogen coating [5] on the surface of steel or iron matrix have been reported elsewhere. S. Barzilai and N. Frage [3] have developed an effective method, which thin films of niobium $(\sim 8 \mu \mathrm{m})$ were deposited on an ATJ graphite substrate by radio-frequency magnetron sputtering at low temperatures $(420 \pm 50 \mathrm{~K})$ under argon pressure of $0.67 \mathrm{~Pa}$. It was found that the activation energies are $190 \mathrm{~kJ} / \mathrm{mol}$ for $\mathrm{Nb}_{2} \mathrm{C}, 164 \mathrm{~kJ} / \mathrm{mol}$ for $\mathrm{NbC}$, and $169.4 \mathrm{~kJ} / \mathrm{mol}$ for the combined carbide layers, respectively.

The main goal of this study is to study the kinetics of two layers vanadium carbide $\left(\mathrm{V}_{2} \mathrm{C}\right.$ and $\left.\mathrm{V}_{8} \mathrm{C}_{7}\right)$ reinforced iron matrix surface composite, which were prepared by solid phase diffusion reaction.

\section{Experimental procedures}

The main raw materials for preparing two layers vanadium carbide are vanadium plate (wt.\%, $99.97 \mathrm{~V}$ ) and gray cast iron (wt.\%, 2.57C-1.04Mn-1.03Si$0.046 \mathrm{P}-0.018 \mathrm{~S}$ ). The two layers vanadium carbide reinforced iron matrix surface composite were prepared by solid-phase diffusion reaction process. The details of the process are presented in the author's prior work [6]. Each specimen was heated to $1373 \mathrm{~K}$ and maintained for $5 \mathrm{~min}$, followed by incubation at 1223,1273 , and $1323 \mathrm{~K}$ for 30-240 $\mathrm{min}$ in a horizontal tube furnace with a modest flow of argon $(5 \mathrm{~mL} / \mathrm{min})$.

After being polished with diamond paste and etched with a $4 \%$ Nital solution, the microstructures of specimens were examined using a JSM-5800 scanning electron microscope (JEOL, Japan) equipped with an energy dispersive X-ray spectroscopy (EDS). The X-ray diffraction (XRD) data were recorded on a PW $1730 \mathrm{X}$ ray diffractometer (Philips, The Netherlands) with monochromated $\mathrm{Cu} \mathrm{K \alpha}$ radiation at $40 \mathrm{kV}$ and $40 \mathrm{~mA}$ in the $2 \theta$ range of $20-90^{\circ}$.

\section{Results and discussion}

\subsection{Microstructure of the vanadium carbide reinforced iron matrix surface composite.}

Fig. 1 is the microstructure of the vanadium carbide reinforced iron matrix surface composites by incubation at $1223 \mathrm{~K}$ for $30 \mathrm{~min}, 60 \mathrm{~min}, 120 \mathrm{~min}$, and $240 \mathrm{~min}$ after high temperature treatment at $1373 \mathrm{~K}$ for $5 \mathrm{~min}$, respectively. It is clear that, there are two dense and compact layers between vanadium plate and the matrix, which have good bonding to the gray cast iron. In detail, the longitudinal cross-section microstructure of the composite can be divided into two layers: light gray layer ( I ) and dark gray layer ( II ). The location of layer I is close to the vanadium plate, and its thickness are only $6 \sim 15 \mu \mathrm{m}$ with dense carbide. Layer II shows less density and carbide distribution with $21 \sim 61 \mu \mathrm{m}$ in thickness. Besides, the thicknesses of the layers gradually increase

\footnotetext{
a Corresponding author: zhonglisheng@xaut.edu.cn
} 
with the heat treatment times increased from $30 \mathrm{~min}$ to $240 \mathrm{~min}$.

Fig. 2 is the XRD results of the vanadium carbide reinforced iron matrix surface composites by incubation at $1223 \mathrm{~K}$ for $30 \mathrm{~min}, 60 \mathrm{~min}, 120 \mathrm{~min}$, and $240 \mathrm{~min}$ after high temperature treatment at $1373 \mathrm{~K}$ for $5 \mathrm{~min}$, respectively. The XRD results showed that $\mathrm{V}, \mathrm{V}_{8} \mathrm{C}_{7}$, and $\mathrm{V}_{2} \mathrm{C}$ are the main phases of the composites. By prolonging heat treatment time from $30 \mathrm{~min}$ to $240 \mathrm{~min}$, the intensities of the diffraction peaks corresponding to metallic vanadium decrease along with increasing the intensities of the diffraction peaks of $\mathrm{V}_{8} \mathrm{C}_{7}$ and $\mathrm{V}_{2} \mathrm{C}$. The author's previous work [7] shows that layer $\mathrm{I}$ and layer II are $\mathrm{V}_{2} \mathrm{C}$ layer and $\mathrm{V}_{8} \mathrm{C}_{7}$ dense layer, respectively.
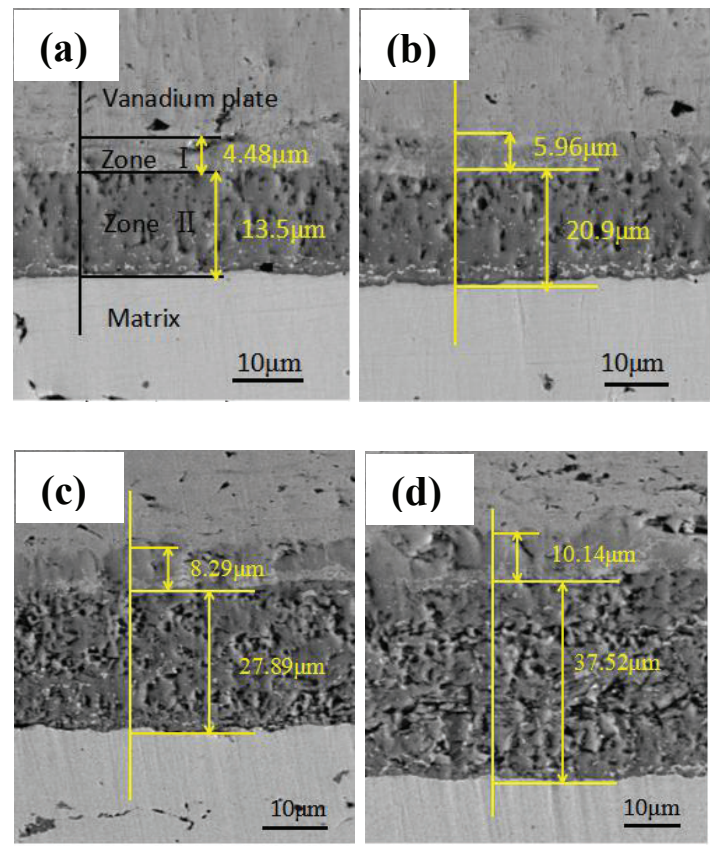

Figure.1. Microstructure of the vanadium carbide reinforced iron matrix composite by incubation at $1223 \mathrm{~K}$ for $30 \mathrm{~min}$ (a), $60 \mathrm{~min}$ (b), 120 min (c), and $240 \mathrm{~min}$ (d), after high temperature treatment at $1373 \mathrm{~K}$ for $5 \mathrm{~min}$, respectively.

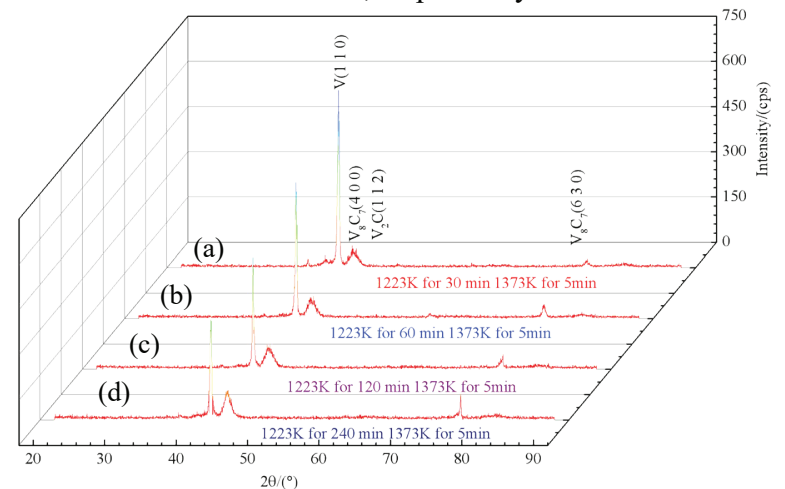

Figure.2. XRD results of the vanadium carbide reinforced iron based surface composites by incubation at $1223 \mathrm{~K}$ for 30 (a), 60 (b), 120 (c), and $240 \mathrm{~min}$ (d) after high temperature treatment at $1373 \mathrm{~K}$ for $5 \mathrm{~min}$.

To obtain more information on the layer I and layer II in the composite, the specimen by incubation at 1223 $\mathrm{K}$ for $240 \mathrm{~min}$ were examined. According to the EDS results obtained from the crystalline particles present in each layer, the ratio of vanadium to carbon is 1:0.55 and 1:0.93 for the layers of I and II, respectively, in the specimen heat treated at $1223 \mathrm{~K}$ for $240 \mathrm{~min}$. Based on the XRD results, these values are considered to be close to the atomic ratio of $\mathrm{V}_{2} \mathrm{C}$ and $\mathrm{V}_{8} \mathrm{C}_{7}$, respectively.
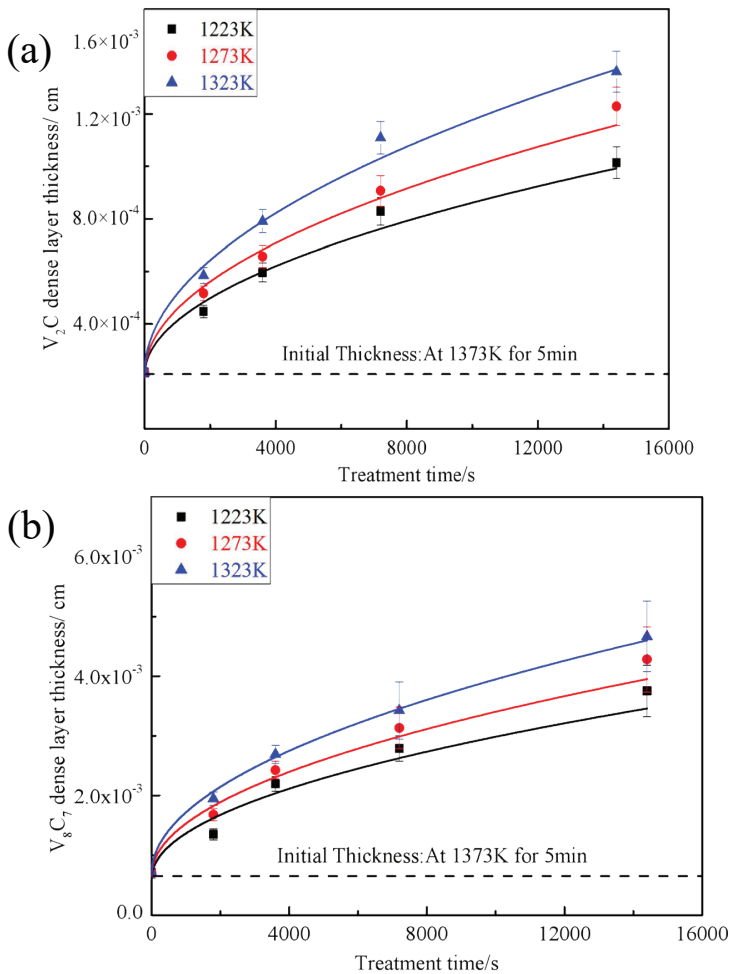

Figure.3. Two layers thickness increases with treatment time for each process temperature for $\mathrm{V}_{2} \mathrm{C}$ layer (a) and $\mathrm{V}_{8} \mathrm{C}_{7}$ layer (b).

\subsection{Kinetics of two layers vanadium carbide reinforced iron matrix surface composites.}

The experiments can measure the $\mathrm{V}_{2} \mathrm{C}$ and $\mathrm{V}_{8} \mathrm{C}_{7}$ layers thickness. These measured values can be used to calculate the kinetics parameters of the vanadium carbide reinforced layer. The graphical representation in Fig.3 shows that two layers thickness increases with treatment time for each process temperature. It was observed that the longer the treatment time and the higher the process temperature, the thicker carbide layer became. On the basis of the classical kinetic theory.

Fig.4 shows the square of the layer thickness versus treating time at different temperatures. It is clear that the square of the layer thickness changes linearly with the treating time. The fitted six straight lines in Fig.4 correlation coefficients $\mathrm{R}^{2}$ are higher than 0.98 , indicating that it is credible that the growth rate constant $\mathrm{K}$ at the same temperature conditions is a constant.

In addition, the relationships between the growth rate constant K, activation energy Q, and the process temperature in Kelvin $\mathrm{T}$, can be expressed as an Arrhenius equation [8]:

$$
\ln K=\ln \left(K_{0}\right)-\frac{Q}{R T}
$$


where $\mathrm{K}_{0}$ is the pre-exponential constant and $\mathrm{R}$ is the gas constant $(8.314 \mathrm{~J} / \mathrm{mol} \mathrm{K})$. Q and $\mathrm{K}_{0}$ can be calculated from a plot of $\ln \mathrm{K}$ versus $1 / \mathrm{T}$. The activation energy, $\mathrm{Q}$ is the slope of line in Fig.5. It can be seen the value of $\mathrm{Q}$ for $\mathrm{V}_{2} \mathrm{C}$ layer and $\mathrm{V}_{8} \mathrm{C}_{7}$ layer are $47.27 \mathrm{~kJ} / \mathrm{mol}$ and 32.26 $\mathrm{kJ} / \mathrm{mol}$, and the value of $\mathrm{K}_{0}$ for $\mathrm{V}_{2} \mathrm{C}$ layer and $\mathrm{V}_{8} \mathrm{C}_{7}$ layer are $7.26 \times 10^{-3} \mathrm{~cm}^{2} / \mathrm{s}$ and $6.31 \times 10^{-3} \mathrm{~cm}^{2} / \mathrm{s}$, respectively.

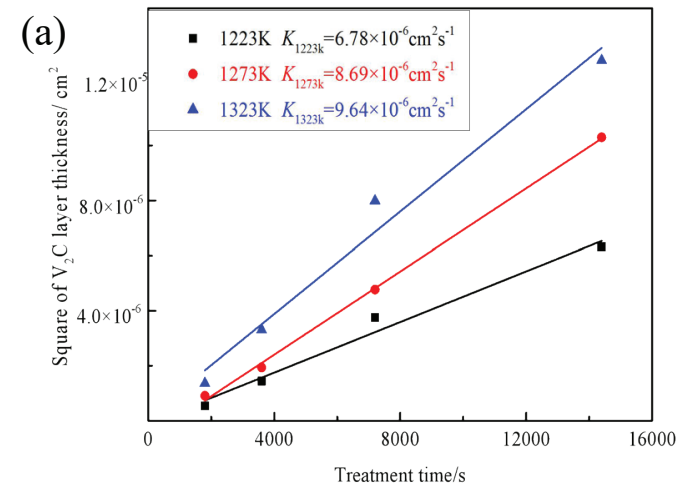

(b)

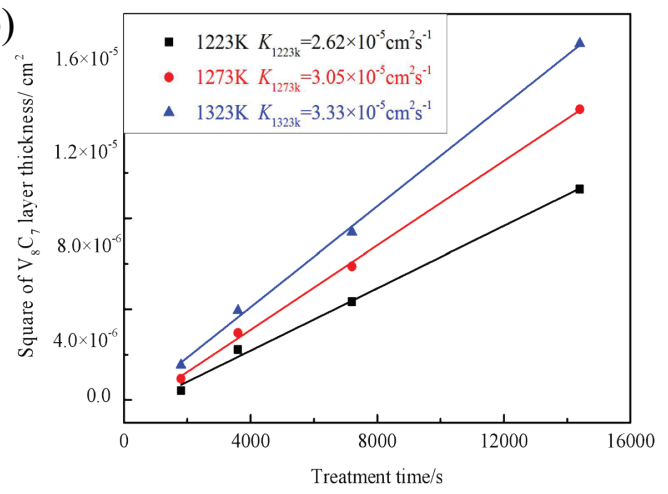

Figure.4. The square of the layer thickness versus treating time at different temperatures for $\mathrm{V}_{2} \mathrm{C}$ layer (a) and $\mathrm{V}_{8} \mathrm{C}_{7}$ layer (b).

(a)

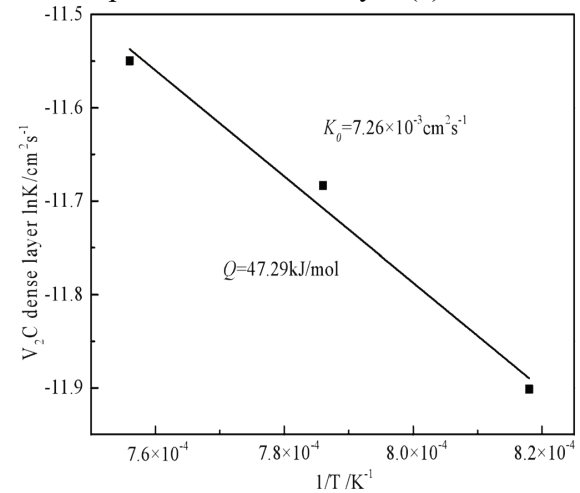

(b)

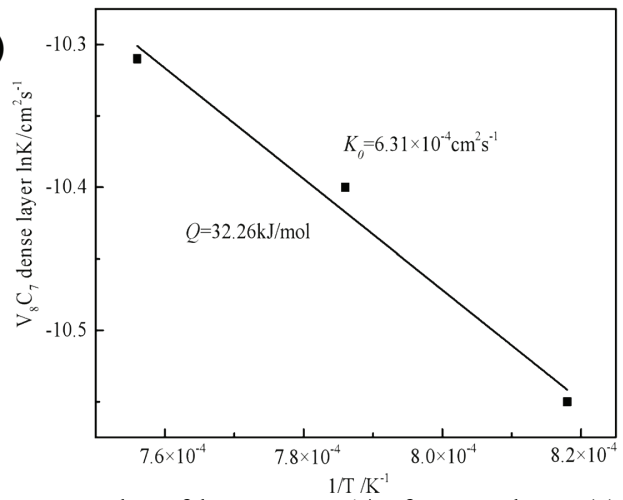

Figure.5. A plot of $\ln \mathrm{K}$ versus $1 / \mathrm{T}$ for $\mathrm{V}_{2} \mathrm{C}$ layer (a) and $\mathrm{V}_{8} \mathrm{C}_{7}$ layer (b).
Inserting the values of $\mathrm{Q}$ and $\mathrm{K}_{0}$ in Eq. (1), Eq. (2) are obtained by inserting the calculated value of $\mathrm{Q}$ and $\mathrm{K}_{0}$. For $\mathrm{V}_{2} \mathrm{C}$ layer and $\mathrm{V}_{8} \mathrm{C}_{7}$ layer, the $\mathrm{K}$ are,

$$
\begin{aligned}
& K=7.26 \times 10^{-3} \exp \left(-\frac{3930.52}{T}\right) \\
& K=6.31 \times 10^{-3} \exp \left(-\frac{3880.03}{T}\right)
\end{aligned}
$$

Then, the relationship among $\mathrm{V}_{2} \mathrm{C}$ layer or $\mathrm{V}_{8} \mathrm{C}_{7}$ layer thickness, treating time and temperature can be obtained.

\section{Conclusions}

The kinetics of composite layer showed that a parabolic relationship between carbide layer thickness and treatment time, which indicating that the composite layer growth kinetics is controlled by diffusion. The relationship between growth rate constant and reaction temperature meet the classical Arrhenius Equation. The apparent activation energy of $\mathrm{V}_{2} \mathrm{C}$ layer and $\mathrm{V}_{8} \mathrm{C}_{7}$ layer were $47.27 \mathrm{~kJ} / \mathrm{mol}$ and $32.26 \mathrm{~kJ} / \mathrm{mol}$, respectively.

\section{Acknowledgements}

The project was supported by the Shaanxi Natural Science Basic Research Project (2016JQ5044) and the Scientific Research Plan Projects of Shaanxi Education Department (16JK1561).

\section{References}

1. X.J. Di, M. Li, Z.W. Yang. Mater.Des. 96 (2016)

2. Y.P. Ji, S.J. Wu , L.J. Xu. Wear. 295, 31 (2012)

3. S. Barzilai, N. Frage, A. Raveh. Surf. Coat. Technol. 200 (2006)

4. V. Ataibis, S. Taktak. Surf. Coat. Technol. 279 (2015)

5. H. Liu , J.C. Li, Y.T. Chai. Surf. Coat. Technol. 302 (2016)

6. S.Z. Fan. L.S. Zhong, Y.H Xu, Y.H. Fu, L.L. Wang. Adv. Eng. Mater. 17, 11 (2015)

7. F.X. Ye, M. Hojamberdiev, Y.H. Xu. Appl. Surf. Sci. 280, 8 (2013)

8. M. Aghaie-Khafri , F. Fazlalipour, J. Phys. Chem. Solids. 69, 10(2008)EPL, 84 (2008) 